\title{
Satisfaction with Health Services among the Citizens of Serbia
}

\author{
Natasa M. Mihailovic ${ }^{1 *}$, Sanja S. Kocic ${ }^{1,2}$, Goran Trajkovic ${ }^{3}$ and Mihajlo Jakovljevic ${ }^{4}$ \\ ${ }^{1}$ Department of Social Medicine, Institute of Public Health Kragujevac, Kragujevac, Serbia, ${ }^{2}$ Department of Social Medicine, \\ Faculty of Medical Sciences, University of Kragujevac, Kragujevac, Serbia, ${ }^{3}$ Faculty of Medicine, Institute for Medical \\ Statistics and Informatics, University of Belgrade, Belgrade, Serbia, ${ }^{4}$ Health Economics and Pharmacoeconomics, Faculty of \\ Medical Sciences, University of Kragujevac, Kragujevac, Serbia
}

Keywords: satisfaction, health care utillitation, inequality, determinants, health systems

\section{SATISFACTION WITH HEALTH SERVICES}

The health system in Serbia has changed a lot in the past 30 years. After falling apart of Yugoslavia in the 90s, all the weaknesses of the health system of that time have become more visible. The

\section{OPEN ACCESS}

Edited by:

Jean-Paul Deslypere,

Proclin Therapeutic Research Pte Ltd

Singapore

Reviewed by:

Maria Margarita Salazar-Bookaman,

Central University of Venezuela,

Venezuela

Brian Godman,

Karolinska Institutet, Sweden

${ }^{*}$ Correspondence:

Natasa M. Mihailovic natalimihailovic@gmail.com

Specialty section:

This article was submitted to Pharmaceutical Medicine and

Outcomes Research,

a section of the journal

Frontiers in Pharmacology

Received: 29 November 2016

Accepted: 23 January 2017

Published: 09 February 2017

Citation:

Mihailovic NM, Kocic SS, Trajkovic G and Jakovljevic M (2017) Satisfaction

with Health Services among the

Citizens of Serbia.

Front. Pharmacol. 8:50.

doi: 10.3389/fphar.2017.00050 country has entered the period of transition, and the creators of health policies have been forced to start the reforms of the health system related to solving structural and functional issues, human resources issues, financing, organization, and availability of the health care in order to build a generally accepted and maintainable health system which shall include intensive controls of the expenses (Kutney-Lee et al., 2009; Kutzin et al., 2010; Jakovljevic et al., 2011; Jakovljevic, 2013).

Following democratic changes during 2000, Serbia has entered the period of intensive reforms and speedy recovery of the health system, due to the significant income of money through International charity help and affordable bank loans (Bajec et al., 2008). Quick development was stopped by the world economic crisis in 2007 (Marmot et al., 2013; Ruckert and Labonté, 2014; Tøge and Blekesaune, 2015). Today, Serbian government provides the health system with $10.4 \%$ of Gross domestic product (GDP), and alongside with Belgium, Denmark, and Canada, Serbia falls under the category of countries which provides health system with a significant part of GDP, but that percentage is considerably smaller than in the countries already mentioned (The World Bank, 2016).

The reform analysis of health systems going through a transition and the analysis of quality assessment of the provided services are conducted using the indicators for the subjective and objective assessment. The most common indicators for the subjective assessment are: the satisfaction of the patient with health care and self-assessment of a health condition. The satisfaction with health care is used in the reform analysis of the health systems all across Europe, Asia and America and it represents the ratio between the expected and achieved health services (Bleich et al., 2009; Browne et al., 2010; Rechel et al., 2012; Gupta et al., 2015).

The most common determinants of the satisfaction of the citizens with health care are: age, health condition, income, the type of the given service (state or private sector), communication, politeness of the staff, and hospital environment (Friese et al., 2008; Aiken et al., 2011, 2012; Al-Refaie, 2011; Xesfingi and Vozikis, 2016).

Due to the lack of universal instrument for measuring the level of satisfaction with health care and the lack of correlation of the satisfaction and economic power of the health system, the degree of satisfaction with health services is determined indirectly based on: waiting lists, quality of given services and communication with health workers (Sofaer and Firminger, 2005; Adang and Borm, 2007). 


\section{THE DATA REPORT METHODS}

\section{Public Data Set Description-National Health Survey Serbia 2006 and 2013}

The research has used the database of the two National Health Surveys in the Republic of Serbia, conducted in 2006 and 2013, funded by the Ministry of Health (National health survey Serbia, 2006, 2013). The survey was conducted in accordance with the methodology and instruments of the European Health Interview Survey wave 2 (Eurostat European Commission, 2013). Both surveys were conducted as cross sectional studies. Population presented in the research included adults, aged 19, and more. The researches excluded people living on the territory of Kosovo and Metohija, as well as people with residence addresses in Special institutions (retirement homes, prisons, psychiatric clinics).

The research used the national representation sample, such as stratified two-phase sample without repetition. The sample frame in the 2006 and 2013 researches included all the households listed in the censuses from 2002 to 2011. In order to obtain a random sample, two techniques have been used: stratification and multiple-phase sampling. Stratification was conducted in such a way that each of six geographical areas in 2006 (Vojvodina, Belgrade, west Serbia, central Serbia, east Serbia, and south-east Serbia) and 4 in 2013 (Vojvodina, Belgrade, Sumadija, and west Serbia, south and east Serbia) represented one main stratum in the sample. Each stratum was divided into cities and other regions. Total number of strata was 12 in 2006 and 8 in 2013. Based on such sample, it is possible to obtain a statistically accurate assessment of the health service quality on a national level as well as on the level of given geographical regions and on the level of cities and other areas.

Two-phase sampling includes local communities, as units of the first phase, selected on the basis of probability proportional to their size, and households as units of the second phase selected on the basis of linear sampling method with the random start and uniform selection steps. In this way, households are selected with the equal probability of being chosen, without repetition.

Acquired data are then united in the unique database according to the common key and organization principle.

\section{Survey Data Description}

The number of households which wanted to participate in the research was significantly different in 2006 and 2013. In 2006 out of 7673 contacted households, 6156 agreed to take part in the research, which represents the response rate of $86.5 \%$. In 2013 the response rate was $64.4 \%$, which means that only 6500 households out of 10,089 contacted ones agreed to participate in the research. Total number of the interviewed adults was 30,186. For the purposes of this paper, the sample of 19-year-olds and older was used, which amounts to the total number of 29,485 interviewees, namely 15,563, and 13,992 in 2006 and 2013 respectively.

Two types of questionnaires have been used in the research: the questionnaires about the household which provided information on the characteristics of the household, residence, and members and the face to face interview which provided data on demographic and socio-economic characteristics of the interviewees. Each interviewee was familiar with the type and the purpose of the research and each of them gave their written consent. Ethical standards in the research were in accordance with the international ethical standards as well as with the Serbian legislation.

Dependent variable in the research was the satisfaction of patients with the health service, measured with Likert-type scale.

Independent variables in the research were:

(a) Basic characteristics of the interviewees (age, gender, financial condition according to well-being index, region). Age is continuous, gender is coded as male, or female, financial condition according to well-being index for the purpose of this paper was coded into three categories: poor, middle class and rich and the listed regions were Vojvodina, Belgrade, Sumadija with West Serbia and South and East Serbia;

(b) Health condition of the interviewees (presence of some illness or certain pathological conditions in the past 12 months, sick leave). Illnesses or pathological conditions which were diagnosed in the past 12 months included: asthma, chronic bronchitis, chronic obstructive pulmonary disease, emphysema, myocardial infarction, coronary heart disease, hypertension, stroke, osteoarthritis, diabetes, kidney problems, depression, malignant diseases, and interviewees were or were not on a sick leave during the past 12 months;

(c) Using hospital and non-hospital health care services and prevention check-ups (hospital treatment choosing a GP or pediatrician, using the private practice services, prevention check-ups, lab analysis, and tension measurement in the health institutions). All these variables are dichotomic;

(d) Unachieved need for health care (lack of some type of health care service due to long waiting lists, financial reasons, long distance of the health institution). Interviewees could or couldn't get the necessary health treatment in the past 12 months due to long waiting lists;

The data set has been submitted in a public repository Figshare and it is a available on: https://figshare.com/s/ b1ede3b1bbcdf166eac7.

\section{Satisfaction with Health Services in Serbia}

During the analyzed period, the percentage of the interviewees satisfied with health care rose from 42.8 to $54.8 \%$. Both with men and women, there is a noticeable increase of the satisfaction level and the satisfied patients were 1 year older in 2013 in comparison to 2006 (52.27 \pm 17.45 , in comparison to $53.86 \pm$ 17.98, $p<0.001)$. The inhabitants of the region of Sumadija and West Serbia were the most satisfied in 2006, while in 2013 the people of Vojvodina were the most satisfied ones. The least satisfied were the rich, namely $39.2 \%$ in 2006 and $48.1 \%$ in 2013 . The interviewees which were diagnosed with some disease in the past 12 months were equally satisfied as those who were not diagnosed with any disease. Patients who were on sick leave in the past 12 months were less satisfied while the difference in satisfaction between hospitalized and not hospitalized patients which was noticed in 2006 (55.6\% of hospitalized as opposed to $41.9 \%$ not hospitalized) faded away and the percentages became identical in 2013. The biggest difference in patient 
TABLE 1 | The comparison of the patients who were satisfied with health care in 2006 and 2013.

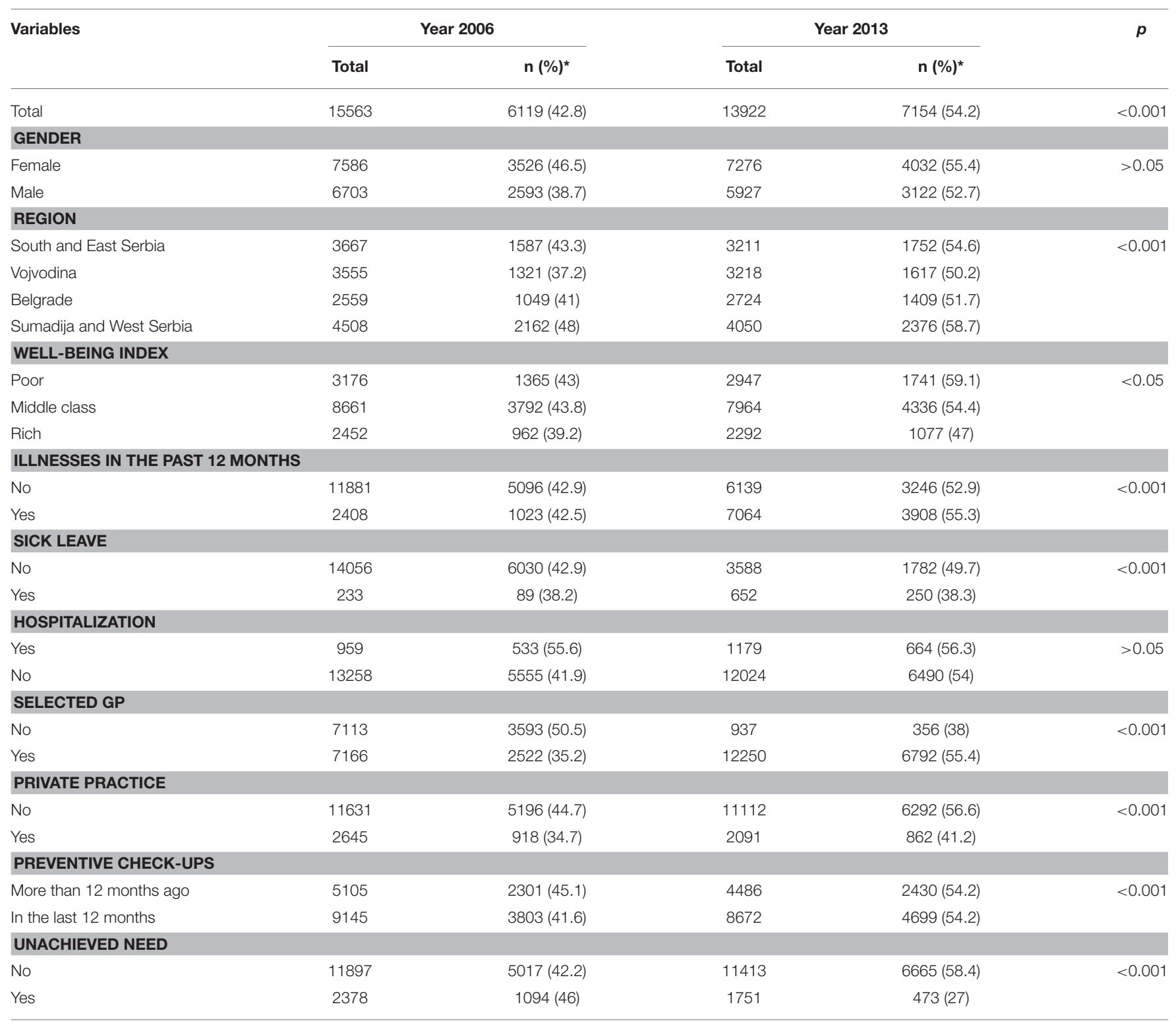

$n(\%)^{*}$, the number (percentage) of whose satisfied with health care.

satisfaction (apart from the variable of unachieved need) was recorded in choosing a general practitioner. In 2006, 50\% of the interviewees had their own GP and one third of the total number of the interviewees were satisfied. The percentage of those who used the private practice services and who were satisfied with them was 34.7 and $41.4 \%$ in 2006 and 2013 respectively, and the percentage of those who had preventive check-ups in the last 12 months was 41.6 and $54.6 \%$ respectively. Almost half of the total number of interviewees in 2006 expressed their satisfaction although they did not get the necessary treatment on time. On the other hand, in 2013 only one quarter of the total number of the interviewees who did not get the necessary treatment on time, were satisfied with the provided services (Table 1).
The results of the binary logistic regression of the patient satisfaction with health care in the period from 2006 to 2013 show that the following variables give a statistically significant contribution to the model: age, illnesses diagnosed in the past 12 months, hospitalization, selected GP, using the private practice services and preventive check-ups in the past 12 months. In 2006, there were more statistically significant predictor variables: region and well-being index, and in 2013 there was sick leave and unachieved need for some type of health care (Table 2).

The older the interviewees were, the less satisfied they were. Odds ratio with patients who were diagnosed with some illness was 1212 (1102-1333) in 2006 and $1182(1027-1361)$ in 2013. Patients who were not hospitalized in the last 12 months were 1.5 or 1.4 times more dissatisfied with health care in comparison 
TABLE 2 | Binary logistic regression for Health Services Satisfaction in 2006 and 2013.

\begin{tabular}{|c|c|c|c|c|}
\hline \multirow[t]{2}{*}{ Variables } & \multicolumn{2}{|c|}{ Year 2006} & \multicolumn{2}{|c|}{ Year 2013} \\
\hline & OR (95\% Cl) & $p$ & OR $(95 \% \mathrm{Cl})$ & $p$ \\
\hline Age & $0.992(0.990-0.994)$ & $<0.001$ & $0.993(0.987-1.000)$ & $<0.05$ \\
\hline \multicolumn{5}{|l|}{ REGION } \\
\hline South and East Serbia & 1 & & 1 & \\
\hline Vojvodina & $1.337(1.213-1.475)$ & $<0.001$ & $1.141(0.944-1.379)$ & $>0.05$ \\
\hline Belgrade & $1.293(1.153-1.449)$ & $<0.001$ & $0.878(0.722-1.066)$ & $>0.05$ \\
\hline Sumadija and West Serbia & $0.0804(0.734-0.880)$ & $<0.001$ & $0.917(0.769-1.094)$ & $>0.05$ \\
\hline \multicolumn{5}{|l|}{ WELL-BEING INDEX } \\
\hline Poor & 1 & & 1 & \\
\hline Middle class & $0.900(0.825-0.982)$ & $<0.05$ & $0.985(0.802-1.208)$ & $>0.05$ \\
\hline Rich & $0.994(0.880-1.122)$ & $>0.05$ & $1.123(0.888-1.421)$ & $>0.05$ \\
\hline \multicolumn{5}{|c|}{ ILLNESSES IN THE PAST 12 MONTHS } \\
\hline No & 1 & & 1 & \\
\hline Yes & $1.212(1.102-1.333)$ & $<0.001$ & $1.182(1.027-1.361)$ & $<0.05$ \\
\hline \multicolumn{5}{|l|}{ SICK LEAVE } \\
\hline No & 1 & & 1 & \\
\hline Yes & 1.249 (0.948-1.646) & $>0.05$ & $1.390(1.141-1.694)$ & $<0.05$ \\
\hline \multicolumn{5}{|l|}{ HOSPITALIZATION } \\
\hline Yes & 1 & & 1 & \\
\hline No & $1.551(1.349-1.783)$ & $<0.001$ & 1.465 (1.070-2.006) & $<0.05$ \\
\hline \multicolumn{5}{|l|}{ SELECTED GP } \\
\hline No & 1 & & 1 & \\
\hline Yes & $2.010(1.867-2.164)$ & $<0.001$ & $0.506(0.391-0.655)$ & $<0.001$ \\
\hline \multicolumn{5}{|l|}{ PRIVATE PRACTICE } \\
\hline No & 1 & & 1 & \\
\hline Yes & 1.556 (1.417-1.708) & $<0.001$ & $1.626(1.359-1.944)$ & $<0.001$ \\
\hline \multicolumn{5}{|l|}{ PREVENTIVE CHECK-UPS } \\
\hline More than 12 months ago & 1 & & 1 & \\
\hline In the past 12 months & $1.124(1.047-1.207)$ & $<0.05$ & 1.199 (1.055-1.364) & $<0.05$ \\
\hline \multicolumn{5}{|l|}{ UNACHIEVED NEEDS } \\
\hline No & 1 & & 1 & \\
\hline Yes & 0.914 (0.833-1.003) & $>0.05$ & 4.576 (3.553-5.892) & $<0.001$ \\
\hline
\end{tabular}

with those who were hospitalized. Less satisfied were those who had preventive check-ups in the last 12 months with those who did not. The biggest difference was recorded with the predictor variable of the selected GP, namely $O R=2.010$ (1867-2164) in 2006 and in 2013 OR $=0506$ (0391-0655). The interviewees who used private practice services were 1.5 and 1.6 times less satisfied in comparison to those who did not use them.

Based on the research from 2006, people coming from Vojvodina and Belgrade were 1.3 and 1.2 times less satisfied in comparison to the people from South and East Serbia.

Based on the research from 2013, patients who were on sick leave had $O R=1390$, which means that they were 1.3 times less satisfied in comparison to the interviewees who were not absent from work. The strongest predictor of patient satisfaction with health care was unachieved need for some type of health protection. Namely, in 2013 patients who did not get the necessary treatment were Four times less satisfied with health care in comparison to those who did not have such problems ( $O R$ $=4579$ (3553-5892).

\section{In Comparison to the World}

The analysis of the patient satisfaction with the health protection services has a goal of improving the quality of the given services, defining priorities, understanding patients' expectations and reducing inequality (Chow et al., 2009; Gupta et al., 2014; Radevic et al., 2016) The researches of the patient satisfaction on a national level enable monitoring of trends, defining problems, analyzing predictors for certain population groups in relation to gender, age, the type of the provided service and the type of the medical institution (U. S. Department of Health Human Services., 2011; Republic of Serbia Ministry of health, 2014). Regardless of possibilities, patient satisfaction with health protection, as a subjective indicator, hasn't still been used in its full scope (Jenkinson et al., 2002; Al-Abri and Al-Balushi, 2014). 
In the period between 2006 and 2013, the population in the Republic of Serbia reduced for $3.3 \%(247,437)$. In the same time, life expectancy increased during the period of about 3 years (it rose from the average 72,37-75,05 years of age for both genders; Institute of Public health of Serbia, 2007, 2014). Health care expenses, by looking at GDP, rose from 9 to $10.4 \%$ of GDP (The World Bank, 2016). However, patient satisfaction as a subjective factor does not have to correlate with the budget and real performance of the health system (Adang and Borm, 2007). Due to the influence of the transition and the related socio-economic changes on patient satisfaction with health care, they have been used in an analysis of relations and attitudes of patients toward the reforms of the health system (Footman et al., 2013). The analysis of the quality indicators related to medical services shows that the satisfaction has significantly decreased in the countries going through a period of transition, especially following the world economic crisis in 2007 (Habibov and Afandi, 2015). Although inequality in using medical services is constantly present (Abebe et al., 2016), there are certain differences related to the period before and after 2007. So the number of those people who consider their health worse after the world economic crisis increased among the inhabitants of Greece, Lithuania, Poland, and Estonia (Vandoros et al., 2013; Zavras et al., 2013; Hessel et al., 2014; Reile et al., 2014).

The analysis conducted in the countries of West and East Europe shows diverse results. The research conducted in six countries of Central and East Europe, shows that there were 10$14 \%$ dissatisfied patients. However, some differences could be noticed, namely, patients from Hungary were the most satisfied while the most dissatisfied patients came from Bulgaria and Ukraine (Stepurko et al., 2016). However, the research of patient satisfaction trends conducted in the Netherlands in the period between 2003 and 2009 showed opposing arguments. Namely, according to one group this period recorded a global rise of patient satisfaction while the others argue that the satisfaction among hospitalized patients decreased from 76 to $66 \%$ (Kleefstra et al., 2015).

Patient satisfaction is related to the positive results of treatments, and such patients are easier to treat although they often ask for additional services, but researches show that satisfaction remains even when the additional requests have not been met (Zolnierek and Dimatteo, 2009; Deyo et al., 2010; ACCORD Study Group et al., 2011; Bertakis and Azari, 2011; Wiener et al., 2011). The research of satisfaction factors shows that the communication with medical workers, along with employment status, education and gender is one of the most important factors influencing patient satisfaction. Moreover, women, less educated people, and unemployed people estimate their own health condition as worse (Zolnierek and Dimatteo, 2009; Sánchez-Piedra et al., 2014).

Similar to our research, there was a research conducted in nine countries of the former SSSR which showed increased patient satisfaction with health care from $19.4 \%$ at the beginning to $40.6 \%$ in the period between 2001 and 2010. Similarly to our country, these countries also recorded that the most satisfied patients were young people, less educated people, people coming from rural places, and those people with generally good health condition (Footman et al., 2013). The analysis of the type of medical services shows that people who rarely use services of the Emergency center and, as in our research, those people who often use hospital services were more satisfied (Fenton et al., 2012). It is interesting that there is no significant relation between the satisfaction of hospitalized patients and hospitalization rate while nursing care, medical care and hospital organization are the most important factors determining the level of satisfaction among hospitalized patients in Germany (Sacks et al., 2015; Kraska et al., 2016).

\section{CONCLUSIVE REMARKS}

Patient satisfaction with health care represents the path toward the improvement of its quality. However, this instrument is most often used in order to define the factors which determine the satisfaction. In order to use it as means of monitoring and improving the quality, it is necessary to acquire additional knowledge about specific aspects of patient experience in relation to their characteristics, but also about the type and characteristics of the health institution which provided the services as well as the type of the provided services.

\section{AUTHOR CONTRIBUTIONS}

All authors listed, have made substantial, direct, and intellectual contribution to the work, and approved it for publication. NM: drafting of manuscript; SK: interpretation of data; GT: analysis of data; MJ: conception and design of the manuscript.

\section{ACKNOWLEDGMENTS}

The study is a part of the 2006 and 2013 National Health Survey for the population of Serbia (excluding Kosovo) that was carried out by the Ministry of Health of the Republic of Serbia with the professional support of the Institute of Public Health of Serbia "Dr. Milan Jovanovic Batut."

\section{REFERENCES}

Abebe, D. S., Anne, G. T., and Dahl, E. (2016). Individual-level changes in self-rated health before and during the economic crisis in Europe. Int. J. Equity Health 15, 1. doi: 10.1186/s12939-015-0290-8

ACCORD Study Group, Gerstein, H. C., Miller, M. E., Genuth, S., Ismail-Beigi, F., Buse, J. B., et al. (2011). Long-term effects of intensive cardiovascular outcomes. N.Engl. J. Med. 364, 818-828. doi: 10.1056/NEJMoa1006524

Adang, E. M., and Borm, G. F. (2007). Is there an association between economic performance and public satisfaction in health care? Eur. J. Health Econ. 8, 279-285. doi: 10.1007/s10198-0070045-6

Aiken, L. H., Cimiotti, J. P., Sloane, D. M., Smith, H. L., Flynn, L., and Neff, D. F. (2011). Effects of nurse staffing and nurse education on patient deaths in hospitals with different nurse work environments. Med. Care 49, 1047-1053. doi: 10.1097/MLR.0b013e3182330b6e 
Aiken, L. H., Sermeus, W., Van den Heede, K., Sloane, D. M., Busse, R., McKee, M., et al. (2012). Patient safety, satisfaction, and quality of hospital care: cross sectional surveys of nurses and patients in 12 countries in Europe and the United States. BMJ 20:1717. doi: 10.1136/bmj.e1717

Al-Abri, R., and Al-Balushi (2014). Patient satisfaction survey as a tool towards quality improvement. Oman Med. J. 29, 3-7. doi: 10.5001/omj.2014.02

Al-Refaie, A. (2011). A structural model to investigate factors affect patient satisfaction and revisit intention in Jordanian hospitals. Int. J. Artif. Life Res. 2, 43-56. doi: 10.4018/jalr.2011100105

Bajec, J., Krstic, G., Pejin-Stokic, L. J., Penev, G. (Economics Institute, Belgrade, Republic of Serbia). (2008). Social Protection and Social Inclusion in the Republic of Serbia. Report. European Commission, Directorate-General for Employment, Social Affairs and Equal Opportunities, Unit E2; May 2008.

Bertakis, K. D., and Azari, R. (2011). Patient-centered care is associated with decreased health care utilization. J. Am. Board Fam. Med. 24, 229-239. doi: $10.3122 /$ jabfm.2011.03.100170

Bleich, S. N., Özaltin, E., and Murray, C. K. (2009). How does satisfaction with the health-care system relate to patient experience? Bull. World Health Organ 87, 271-278. doi: 10.2471/BLT.07.050401

Browne, K., Roseman, D., Shaller, D., and Edgman-Levitan, S. (2010). Analysis \& commentary: measuring patient experience as a strategy for improving primary care. Health Aff. (Millwood) 29, 921-925. doi: 10.1377/hlthaff.2010.0238

Chow, A., Mayer, E. K., Darzi, A. W., and Athanasiou, T. (2009). Patient-reported outcome measures: the importance of patient satisfaction in surgery. Surgery 146, 435-443. doi: 10.1016/j.surg.2009.03.019

Deyo, R. A., Mirza, S. K., Martin, B. I., Kreuter, W., Goodman, D. C., and Jarvik, J. G. (2010). Trends, major medical complications, and charges associated with surgery for lumbar spinal stenosis in older adults. JAMA 303, 1259-1265. doi: 10.1001/jama.2010.338

Eurostat European Commission (2013). European Health Interview Survey (EHIS wave 2) Methodological manual. Publications Office of the European Union. Available online at: http://www.google.rs/ url? $\mathrm{sa}=\mathrm{t} \& \mathrm{rct}=\mathrm{j} \& \mathrm{q}=\& \mathrm{esrc}=\mathrm{s} \&$ source $=$ web $\& \mathrm{~cd}=6 \& \mathrm{cad}=\mathrm{rja} \& u a c t=8 \& v e d=$ 0ahUKEwihjtWdp-vOAhUlApoKHcpJA5sQFghBMAU\&url=https\%3A \%2F\%2Fgroups.ic.nhs.uk\%2FICHSPN\%2FDocuments\%2FEuropean $\% 2520$ Health\%2520Interview\%2520Survey\%2520(EHIS)\%2520wave\%25202 \%2520proposed\%2520questionnaire.xls\&usg=AFQjCNGWWiG0kvVfD_ YdwuWawxU77pwJ1Q\&bvm=bv.131286987,d.bGs

Fenton, J. J., Jerant, A. F., Bertakis, K. D., and Franks, P. (2012). The Cost of Satisfaction: a national study of patient satisfaction, health care utilization, expenditures, and mortality. Arch. Intern. Med. 12, 405-411. doi: 10.1001/archinternmed.2011.1662

Footman, K., Roberts, B., Mills, A., Richardson, E., and McKe, M. (2013). Public satisfaction as a measure of health system performance: a study of nine countries in the former Soviet Union. Health Policy 112, 62-69. doi: 10.1016/j.healthpol.2013.03.004

Friese, C. R., Lake, E. T., Aiken, L. H., Silber, J. H., and Sochalski, J. (2008). Hospital nurse practice environments and outcomes for surgical oncology patients. Health Serv. Res. 43, 1145-1163. doi: 10.1111/j.1475-6773.2007. 00825.x

Gupta, D., Patel, K., and Lis, C. G. (2015). Self-rated health supersedes patient satisfaction with service quality as a predictor of survival in prostate cancer. Health Qual. Life Outcomes 13, 137. doi: 10.1186/s12955-015-0334-1

Gupta, D., Rodeghier, M., and Lis, C. G. (2014). Patient satisfaction with service quality as a predictor of survival outcomes in breast cancer. Support. Care Cancer 22, 129-134. doi: 10.1007/s00520-013-1956-7

Habibov, N., and Afandi, E. (2015). Pre- and post-crisis life-satisfaction and social trust in transitional countries: an initial assessment. Soc. Indic. Res. 121, 503-524. doi: 10.1007/s11205-014-0640-8

Hessel, P., Vandoros, S., and Avendano, M. (2014). The differential impact of the financial crisis on health in Ireland and Greece: a quasi-experimental approach. Public Health 128, 911-919. doi: 10.1016/j.puhe.2014.08.004

Institute of Public health of Serbia. (2007). "Dr Milan Jovanovic Batut". Health Statistical Yearbook Of Republic of Serbia 2006. Beograd: Institute of Public health of Serbia.

Institute of Public health of Serbia (2014). "Dr Milan Jovanovic Batut". Health Statistical YEARBOOK of Republic of Serbia 2013. Beograd: Institute of Public health of Serbia.
Jakovljevic, M., Jovanovic, M., Lazic, Z., Jakovljevic, V., Djukic, A., Velickovic, R., et al. (2011). Current efforts and proposals to reduce healthcare costs in Serbia. Ser. J. Exp. Clin. Res. 12, 161-163. doi: 10.5937/sjecr1104161J

Jakovljevic, M. (2013). Resource allocation strategies in Southeastern European health policy. Eur. J. Health Econ. 14, 153-159. doi: 10.1007/s10198-012-0439-y

Jenkinson, C., Coulter, A., Bruster, S., Richards, N., and Chandola, T. (2002). Patients' experiences and satisfaction with health care: results of a questionnaire study of specific aspects of care. Qual. Saf. Health Care 11, 335-339. doi: $10.1136 /$ qhc.11.4.335

Kleefstra, S. M., Zandbelt, L. C., de Haes, H. J., and Kool, R. B. (2015). Trends in patient satisfaction in Dutch university medical centers: room for improvement for all. BMC Health Serv. Res. 15:112. doi: 10.1186/s12913-015-0766-7

Kraska, R. A., Weigand, M., and Geraedts, M. (2016). Associations between hospital characteristics and patient satisfaction in Germany. Health Expect. doi: 10.1111/hex.12485. [Epub ahead of print].

Kutney-Lee, A., McHugh, M. D., Sloane, D. M., Cimiotti, J. P., Flynn, L., Neff, D. F., et al. (2009). Nursing: a key to patient satisfaction. Health Aff. (Millwood) 28, 669-677. doi: 10.1377/hlthaff.28.4.w669

Kutzin, J., Cashin, C., and Jakob, M. (2010). Implementing Health Financing Reform: Lessons from Countries in Transition. Copenhagen: WHO Regional Office for Europe.

Marmot, M., Bloomer, E., and Goldblatt, P. (2013). The role of social determinants in tackling health objectives in a context of economic crisis. Public Health Rev. $35,1-24$.

National health survey Serbia (2006). Institute of Public health of Serbia "Dr Milan Jovanovic Batut.” Belgrade: Republic of Serbia Ministry of Health, 2007. Available online at: http://www.batut.org.rs/download/publikacije/Finalni \%20izvestaj\%202006.pdf

National health survey Serbia (2013). Institute of Public health of Serbia "Dr Milan Jovanovic Batut." Belgrade: Republic of Serbia Ministry of Health 2014. Available online at: http://www.batut.org.rs/download/publikacije/ IstrazivanjeZdravljaStanovnistvaRS2013.pdf

Radevic, S., Kocic, S., and Jakovljevic, M. (2016). Self-assessed health and socioeconomic inequalities in serbia: data from 2013 national health survey. Front. Pharmacol. 26:140. doi: 10.3389/fphar.2016.00140

Rechel, B., Ahmedov, M., Akkazieva, B., Katsaga, A., Khodjamurodov, G., and McKee, M. (2012). Lessons from two decades of health reform in Central Asia. Health Policy Plan 27, 281-287. doi: 10.1093/heapol/czr040

Reile, R., Helakorpi, S., Klumbiene, J., Tekkel, M., and Leinsalu, M. (2014). The recent economic recession and self-rated health in Estonia, Lithuania and Finland: a comparative cross-sectional study in 2004-2010. J. Epidemiol. Commun Health 68, 1072-1079. doi: 10.1136/jech-2014-204196

Republic of Serbia Ministry of health (2014). Institute of Public health of Serbia "Dr Milan Jovanovic Batut." Analysis of Customer Satisfaction Health Care in Public Health Institutions of the Republic of Serbia 2013. Belgrade. Available online at: http://www.batut.org.rs/download/izvestaji/Zadovoljstvo \%20korisnika\%20ZZ\%202013

Ruckert, A., and Labonté, R. (2014). The global financial crisis and health equity: early experiences from Canada. Glob. Health 10:2. doi: 10.1186/1744-8603-10-2

Sacks, G. D., Lawson, E. H., Dawes, A. J., Russell, M. M., Maggard-Gibbons, M., Zingmond, D. S., et al. (2015). Relationship between hospital performance on a patient satisfaction survey and surgical quality. JAMA Surg. 150, 858-864. doi: 10.1001/jamasurg.2015.1108

Sánchez-Piedra, C. A., Prado-Galbarro, F. J., García-Pérez, S., and Santamera, A. S. (2014). Factors associated with patient satisfaction with primary care in Europe: results from the EUprimecare project. Qual. Prim. Care 22, 147-155.

Sofaer, S., and Firminger, K. (2005). Patient perceptions of the quality of health services. Annu. Rev. Public Health 26, 513-559. doi: 10.1146/annurev.publhealth.25.050503.153958

Stepurko, T., Pavlova, M., and Groot, W. (2016). Overall satisfaction of health care users with the quality of and access to health care services: a cross-sectional study in six Central and Eastern European countries. BMC Health Serv. Res. 16:342. doi: 10.1186/s12913-016-1585-1

The World Bank (2016). Health Expenditure, Total (\% of GDP). Available online at: http://data.worldbank.org/indicator/SH.XPD.TOTL.ZS

Tøge, A. G., and Blekesaune, M. (2015). Unemployment transitions and self-rated health in Europe: a longitudinal analysis of EU-SILC from 2008 to 2011. Soc. Sci. Med 143, 171-178. doi: 10.1016/j.socscimed.2015.08.040 
U. S. Department of Health and Human Services. (2011). Report to Congress: National Strategy for Quality Improvement in Health Care. Washington, DC: U. S. Department of Health and Human Services.

Vandoros, S., Hessel, P., Leone, T., and Avendano, M. (2013). Have health trends worsened in Greece as a result of the financial crisis? A quasi-experimental approach. Eur. J. Pub Health 23, 727-731. doi: 10.1093/eurpub/ckt020

Wiener, R. S., Schwartz, L. M., and Woloshin, S. (2011). Time trends in pulmonary embolism in the United States: evidence of overdiagnosis. Arch. Intern. Med. 171, 831-837. doi: 10.1001/archinternmed.2011.178

Xesfingi, S., and Vozikis, A. (2016). Patient satisfaction with the healthcare system: assessing the impact of socio-economic and healthcare provision factors. BMC Health Serv. Res. 15:94. doi: 10.1186/s12913-016-1327-4

Zavras, D., Tsiantou, V., Pavi, E., Mylona, K., and Kyriopoulos, J. (2013). Impact of economic crisis and other demographic and socio-economic factors on self-rated health in Greece. Eur. J. Pub. Health 23, 206-210. doi: $10.1093 /$ eurpub/cks143
Zolnierek, K. B., and Dimatteo, M. R. (2009). Physician communication and patient adherence to treatment: a metaanalysis. Med. Care 47, 826-834. doi: 10.1097/MLR.0b013e3181 $9 \mathrm{a} 5 \mathrm{acc}$

Conflict of Interest Statement: The authors declare that the research was conducted in the absence of any commercial or financial relationships that could be construed as a potential conflict of interest.

Copyright (c) 2017 Mihailovic, Kocic, Trajkovic and Jakovljevic. This is an openaccess article distributed under the terms of the Creative Commons Attribution License (CC BY). The use, distribution or reproduction in other forums is permitted, provided the original author(s) or licensor are credited and that the original publication in this journal is cited, in accordance with accepted academic practice. No use, distribution or reproduction is permitted which does not comply with these terms. 